\title{
The Influence of Foils Thickness on Recrystallized Structure Observed during In-Situ Heating of AlMgScZr Alloy
}

\author{
$\underline{\text { Miroslav Cieslar }}^{1}$, Barbora Křivská ${ }^{1}$, Michaela Šlapáková ${ }^{1}$, Jan Bajer ${ }^{1}$, Olexandr Grydin ${ }^{2}$ and \\ Mykhailo Stolbchenko². \\ ${ }^{1}$ Charles University, Faculty of Mathematics and Physics, Prague, Czech Republic. \\ ${ }^{2}$ University Paderborn, Faculty of Mechanical Engineering, Paderborn, Germany.
}

AlMg-based alloys exhibit excellent corrosion resistance. Nevertheless, one of their primary disadvantages is their lower strengths for structural applications. Additions of scandium and zirconium offer attractive combination of properties. The precipitation of metastable $\mathrm{Al}_{3}(\mathrm{Sc}, \mathrm{Zr})$ particles during aging delivers contribution from precipitation hardening increasing thus the strength levels of the alloy.

Twin-roll casting (TRC) of such alloys is not a standard procedure but it enables to cast strips with a final thickness equal to the requested one. The microstructure formed during this type of casting contains nearly equiaxed grains [1] that are less susceptible to exfoliation corrosion than flat elongated grains appearing in conventionally cast and rolled materials [2]. This susceptibility is predominantly linked to the precipitation of highly anodic $\mathrm{Al}_{3} \mathrm{Mg}_{2}$ phase along flat grain boundaries [3] Therefore, new approaches of aluminum sheets production are in the center of an intensive research now. TRC is a promising option which does not produce an undesirable fiber structure [4], and moreover could be combined with several methods of severe plastic deformation (SPD) in order to reach further grain refinement and strengthening [5] of the final metal strip.

The evolution of microhardness during annealing at elevated temperatures was studied in a TRC Al$3.24 \% \mathrm{Mg}-0.19 \% \mathrm{Sc}-0.14 \% \mathrm{Zr}$ (wt.\%) alloy with small additions of $\mathrm{Fe}, \mathrm{Mn}$ and $\mathrm{Si}$ as impurities. The material was predeformed by four cycles of equal channel angular pressing (ECAP) at $250{ }^{\circ} \mathrm{C}$ using the route $B_{c}[6]$. Mechanical properties were related to electron microscopy microstructure observations including in-situ heating in the transmission electron microscope (TEM).

In accordance with recent results an increase of microhardness occurs during annealing up to 300 ${ }^{\circ} \mathrm{C}$ (Fig. 1a) due to the formation of a fine dispersion of $\mathrm{Al}_{3}(\mathrm{Sc}, \mathrm{Zr}$ ) particles (Fig. 1b). A two-stage drop of microhardness observed above this temperature is associated with the coarsening and growth of strengthening $\mathrm{Al}_{3}(\mathrm{Sc}, \mathrm{Zr})$ particles and recovery and recrystallization of the deformation structure (Fig. 2a). However, the final grain size observed by TEM during the in-situ heating at highest annealing temperatures was by an order of magnitude smaller than the one generally detected in bulk specimens annealed in a furnace (Fig. 2b).

Electron back scatter diffraction (EBSD) analysis was performed on the in-situ annealed TEM foil (Fig. 3a). Clear distribution of the grain size reflecting the wedge-shape of the foil near the hole in the center of the specimen (Fig. 3b) confirms the negative constraining role of the foil thickness. The grain size near the edge of the hole (area, where the in-situ TEM study was performed) does not exceed several micrometers while in thicker zones of the specimen (generally around $100 \mu \mathrm{m}$ thick) the diameters of grains easily approach several hundreds of micrometers which is the size comparable with the grain diameters observed in bulk specimens. The obtained results clearly indicate the limitation of in-situ experiments to objects of scales not exceeding the thickness of the foil. [7] 


\section{References:}

[1] M Šlapáková et al, Manufacturing Technology 18 (2018), p. 130.

[2] M Liao et al, Int J Fatigue 25 (2003), p. 1059.

[3] KA Yasakau et al, Electrochim Acta 52 (2007), p. 7651.

[4] M Cieslar et al, Manufacturing Technology 16 (2016), p. 1255.

[5] N Hansen, Scripta Materialia 51 (2004), p. 801.

[6] RZ Valiev and TG Langdon, Progress in Materials Science 51 (2006), p. 881.

[7] The financial support of Czech Science Foundation project 16-16218S is highly acknowledged.
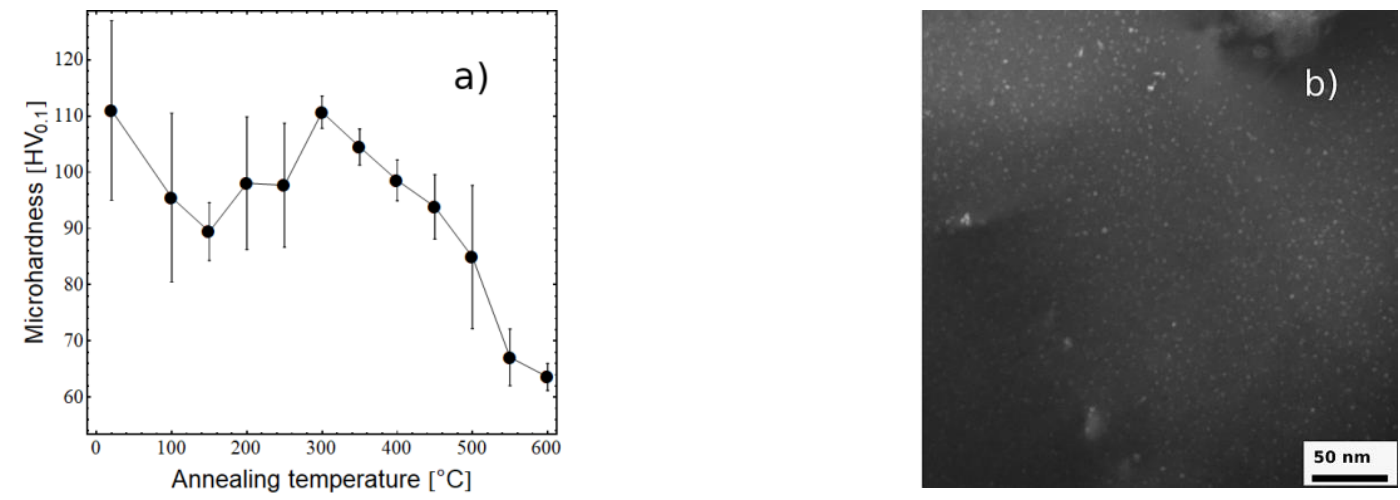

Figure 1. Evolution of microhardness of TRC AlMgScZr alloy predeformed by ECAP during isochronal annealing with the step $50{ }^{\circ} \mathrm{C} / 50 \mathrm{~min}$ (a) and distribution of fine $\mathrm{Al}_{3}(\mathrm{Sc}, \mathrm{Zr})$ precipitates after annealing to $300{ }^{\circ} \mathrm{C}(\mathrm{b})$.
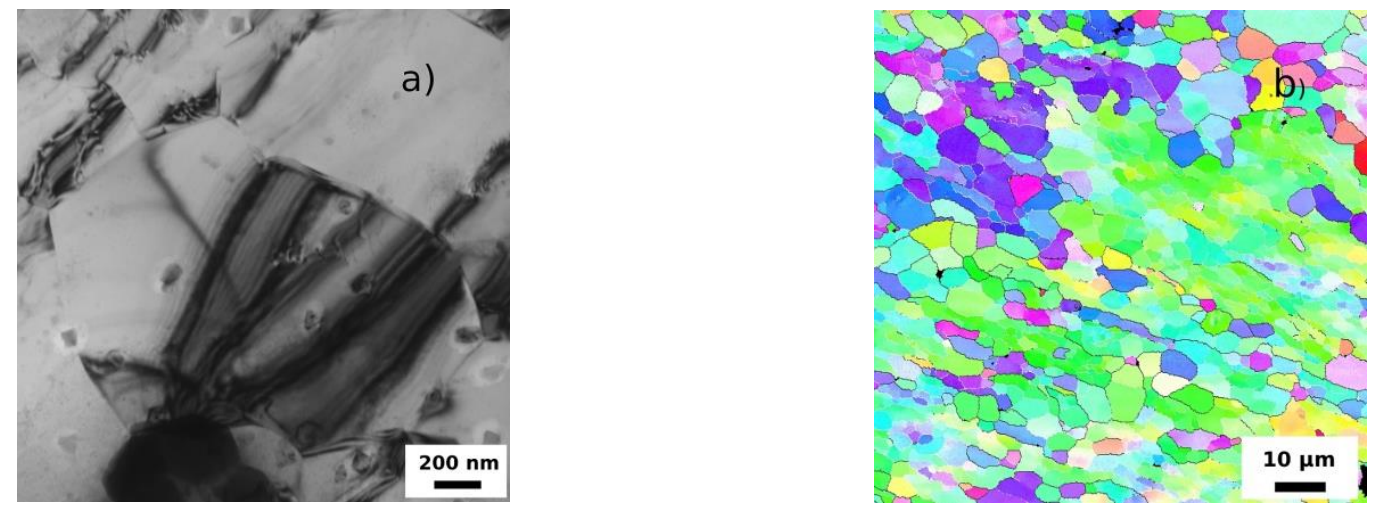

Figure 2. TEM image of grains in TRC AlMgScZr alloy annealed in-situ up to $550{ }^{\circ} \mathrm{C}$ (a) and EBSD map of grains in the bulk specimen annealed up to the same temperature (b).
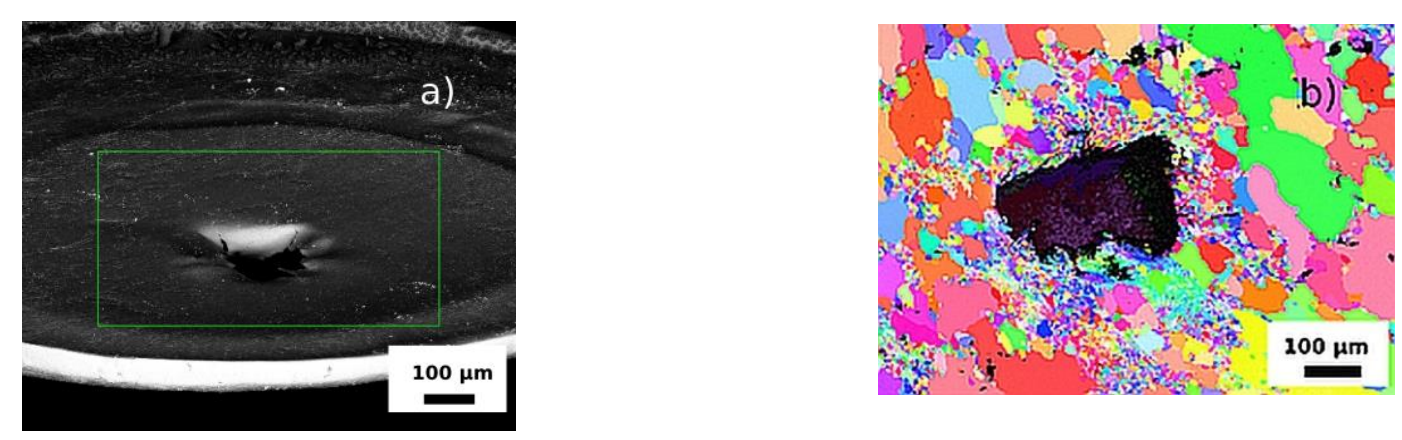

Figure 3. Area selected on a TEM specimen for EBSD analysis (a) and corresponding EBSD map (b). 